\title{
Application of Machine Learning in Google Services- A Case Study
}

\author{
Siji Jose Pulluparambil ${ }^{1} \&$ Subrahmanya Bhat ${ }^{2}$ \\ ${ }^{1}$ Research Scholar, College of Computer Science and Information Science, Srinivas \\ University, Mangalore, India. \\ Orcid ID: 0000-0001-6214-3304, E-mail: sijijohn2223@gmail.com \\ ${ }^{2}$ Professor, College of Computer Science and Information Science, Srinivas University, \\ Mangalore, India. \\ Orcid ID: 0000-0003-2925-1834; E-mail: itsbhat@gmail.com
}

Area of the Paper: Computer Science.

Type of the Paper: Research Case Study.

Type of Review: Peer Reviewed as per $|\mathrm{C}| \mathrm{O}|\mathrm{P}| \mathrm{E} \mid$ guidance.

Indexed In: OpenAIRE.

DOI: http://doi.org/10.5281/zenodo.5145505

Google Scholar Citation: $\underline{\text { IJCSBE }}$

\section{How to Cite this Paper:}

Pulluparambil, Siji Jose, \& Bhat, Subrahmanya, (2021). Application of Machine Learning in Google Services- A Case Study. International Journal of Case Studies in Business, IT, and Education (IJCSBE), 5(2), 24-37. DOI: http://doi.org/10.5281/zenodo.5145505.

International Journal of Case Studies in Business, IT and Education (IJCSBE)

A Refereed International Journal of Srinivas University, India.

Crossref DOI : https://doi.org/10.47992/IJCSBE.2581.6942.0117

(C) With Authors.

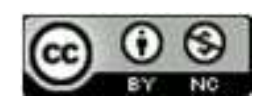

This work is licensed under a Creative Commons Attribution Non-Commercial 4.0 International License subject to proper citation to the publication source of the work.

Disclaimer: The scholarly papers as reviewed and published by the Srinivas Publications (S.P.), India are the views and opinions of their respective authors and are not the views or opinions of the S.P. The S.P. disclaims of any harm or loss caused due to the published content to any party. 


\title{
Application of Machine Learning in Google Services- A Case Study
}

\author{
Siji Jose Pulluparambil ${ }^{1} \&$ Subrahmanya Bhat ${ }^{2}$ \\ ${ }^{1}$ Research Scholar, College of Computer Science and Information Science, Srinivas \\ University, Mangalore, India. \\ Orcid ID: 0000-0001-6214-3304, E-mail: sijijohn2223@gmail.com \\ ${ }^{2}$ Professor, College of Computer Science and Information Science, Srinivas University, \\ Mangalore, India. \\ Orcid ID: 0000-0003-2925-1834; E-mail: itsbhat@gmail.com
}

\begin{abstract}
Purpose: Google Search is currently the most preferred search engine worldwide, making it one of the websites with the highest traffic. It assists people in discovering the content they are searching for, from the large repository of the World Wide Web. Google has grown to be the best in the search engine market that it is the single most important variable to be considered when optimizing a website for search. There are many ranking algorithms used by Google to make the searching process more precise. Google has the vision "to provide access to the world's information in one click". Machine learning is the most popular methodology applied in predicting future outcomes or organizing information to assist people in making required decisions. ML algorithms are trained over instances or examples through which they analyze the historical data available and learn from past experiences. By repeatedly training over the samples, the patterns in the data can be identified in order to make predictions about the future. Google, as an organization, can be a pioneer in $M L$, and as a technology product, can be a use case for machine learning. Here, a case analysis has been prepared on few applications of machine learning in the products and services of Google. Within this paper, we highlight their technological history, services with machine learning applications, financial plans, and challenges. The paper also tries to examine the various products of Google which apply ML, such as Google Maps, Gmail, Google Photos, Google Assistant, and review the algorithms used in each service.

Approach: The detailed survey method on secondary data is used for analysing the data. Findings: Based on the developed case study, it is clearly evident that Google is using machine learning algorithms with few artificial intelligence features to enhance the quality of the services they provide.
\end{abstract}

Originality: A new way of analysis was performed to identify the methods used in the organization's services.

Paper Type: Descriptive Case Study Research

Keywords: Google, Machine Learning, Algorithms, Search Engine.

\section{INTRODUCTION :}

Google is an American multinational company that has established its presence globally and provides various web-based services and products. The search engine space is dominated by Google and it handles about 3.5 billion search queries every day. In other words, Google processes more than 40,000 searches in a second [1]. The founders of Google, Larry Page and Sergey Brin, initiated the search engine project at Stanford University in 1996, while they were PhD students there [2]. Google has over $90 \%$ of the global search engine market share as of June 2021 [3].

Machine learning is one of the subfields of artificial intelligence and tech companies like Google, Facebook, Apple, Microsoft, and even Amazon have contributed greatly in integrating it into our everyday lives. In machine learning, the structure of data is analysed so that it can be fitted into models to derive insights from it. Most of the technologies in use today have benefitted from machine learning. 
Social media platforms use facial recognition technology to help users tag and share photos of friends, which is an application of ML. Optical Character Recognition (OCR) technology converts textual content in images to machine-encoded text which is yet another application of machine learning. With the support of recommendation and ranking algorithms powered by ML, streaming platforms can recommend the movies or shows to watch according to users' choices. The use of recommendation engines has found greater adoption in social media platforms, entertainment services, and even digital news media. It can suggest movies, videos, television shows, articles, and posts based on the user's search history and interests. Hailed as the next revolutionary milestone in mobility, self-driving cars can be considered a wonderful feat achieved through machine learning. The past decade has witnessed the phenomenal growth of machine learning and it has been widely adopted in various industry verticals.ML and $\mathrm{AI}$ are considered to be driving forces in the smart industry revolution, commonly referred to by the term Industry 4.0 [4].

\section{OBJECTIVES OF STUDY :}

This case study explores the various publicly available information on Google products and services which have adopted the advancements in machine learning. The goals and objectives of this study are -

(1) To study the history and development of Google

(2) To familiarize the most commonly used Google services with machine learning applications

(3) To learn about Google's strategy for addressing problems in their services with ML algorithms.

(4) To study the corporate social responsibility (CSR) policy and of Google and the activities undertaken in this regard.

\section{OVERVIEW OF GOOGLE :}

\subsection{Mission and Vision:}

Google has stated that its mission is "to organize the world's information and make it universally accessible and useful" [5]. In the words of its founders, Google was started with the vision to "provide an important service to the world-instantly delivering relevant information on virtually any topic" [6]. In the 2004 Founder's IPO letter, Larry Page mentioned that "serving our end users is at the heart of what we do and remains our number one priority" [7].

\subsection{History of Google:}

The origin of Google can be traced back to "BackRub", a research project by Larry Page and Sergey Brin, started in 1996 when they were both PhD scholars at Stanford University. While Page was looking for a dissertation topic, he investigated the concept of representing the connection structure of the World Wide Web as a graph. The project was given the nickname "BackRub". Sergey Brin joined the project soon afterwards, and at the time, he was working under a National Science Foundation Graduate Fellowship. Even though Larry Page and Sergey Brin are considered the creators of Google, they have acknowledged the help received from Scott Hassan and Alan Stremberg in implementing it [8]. The primary paper about Google was published in 1998, describing the concept of PageRank and the initial design of the Google search engine. The paper was authored by Larry Page, Sergey Brin, Rajeev Motwani and Terry Winograd [9]. The history of Google, spanning more than three decades, has been summarized in the following subsections.

\subsubsection{0-1999:}

Initially, Google operated as a sub-domain of Stanford's website. On September 15, 1997, the google.com domain was officially registered. Google was incorporated as a company a year later, in September 1998.The company operated from their friend and colleague Susan Wojcicki's garage at Menlo Park [10]. Wojcicki later rose to key leadership roles at Google and has been serving as the chief executive officer at YouTube since 2014. In the first few years, both the founders of Google were against the idea of monetizing the search engine by serving ads. In 1998, when Google was in its alpha test phase, the number of webpages indexed by the search engine was close to 60 million [11]. When Google started to gain traffic, Brin and Page decided to sell off their idea to Excite, which was a popular search engine at the time. They approached the executives of Excite and proposed to sell Google for \$1 million. Their offer was turned down by George Bell, CEO of Enron [12]. By the end of the decade, the company moved into new offices in Palo Alto. 


\subsubsection{0-2009:}

By 2000, Google ventured into advertising by displaying ads on the search results page. To conform to Google's clean user interface and maintain the page loading speed, advertisements were limited to text. Advertisers can buy keywords and place their ads on top of the search results, through a price bid or click-through model, with prices starting at \$.05 per click. In February 2004, Yahoo! ended its association with Google's search service and returned to using its own technology in delivering search results [13]. In June 2005, Google's market capitalization was estimated to be $\$ 52$ billion. In 2008, Google launched Knol as a replacement for Wikipedia. Knol did not have a good run and was shut down after four years [14].

\subsubsection{0-2020:}

In 2011, Google+ was launched, the fourth experiment in the line of Google's social media platforms like Google Buzz (2010-2011), Google Friend Connect (2008-2012), and Orkut (2004-2014).It was reported in 2014 Google had 70 physical work locations spread across 41 countries [15].Google underwent corporate restructuring in 2015, wherein a new holding company named Alphabet Inc. was formed and Google was made a subsidiary company under it [16].The conventional products and services were retained by Google, while other projects such as Jigsaw, DeepMind, Calico, and Verily were spun off as independent companies under the parent company Alphabet Inc. [17].

\subsubsection{0-Present:}

October 6, 2020, Google announced the rebranding of G Suite as Google Workspace [18]. With the new platform, there is better integration between the apps such as Google Drive, Gmail, Calendar and Meet. An example would be the option to present a Sheets document directly to Google Meet. Along with the rebranding, the iconic logos for popular Google services like Drive, Gmail, Docs, Meet and other products in Google Workspace were also changed. Fuelling the driverless car dreams, Waymo, formerly the Google self-driving car project, launched their services Waymo One and Waymo Via in 2018 and 2020 respectively [19],[20].

\section{MACHINE LEARNING TECHNOLOGY APPLICATIONS IN GOOGLE :}

Machine learning is rapidly gaining traction around the world and businesses are its greatest benefactor, contributing to the development and popularity of ML, at the same time. ML is expected to become a part of everyday lives, automating repetitive tasks and providing assistance to users through chatbots or voice assistants. Based on the visual, physical, and subjective signals received from a user, ML models can provide insights and actionable information. It is anticipated that machine learning will completely transform the social and economic spheres globally. Google has been one of the early adopters of machine learning in their processes and has ever been a contributor to the technology by developing and maintaining ML libraries, APIs, datasets, and so on. Outlining Google's affinity to machine learning, Sundar Pichai, who currently heads Google and Alphabet, remarked in 2015 that "Machine learning is a core, transformative way by which we are rethinking how we are doing everything" [21]. In the following subsections, an overview of Google products and services that incorporates machine learning is presented.

\subsection{Gmail:}

Gmail is the most widely used e-mail service worldwide. Owing to a large number of users, it is also prone to several security threats. E-mail inboxes can also include malicious attachments and spam messages which can escalate to be a security threat. Behind the scenes, Google tries to block these attachments before reaching our inbox. The deep learning-based document scanners work in association with existing artificial intelligence (AI) and machine learning (ML) mechanisms in Gmail to enhance the document detection capabilities. The scanner is composed of a TensorFlow deep learning model developed in TFX (TensorFlow Extended) and document analysers designated for each type of file (.docx, .pdf, .exe, etc.). These documents analysers parse the content, detect macros and perform feature extraction. Multiple scanners running in parallel to the exiting document detection system helps Gmail's decision engine to classify attachments and block malicious documents [22]. 
Smart Reply and Smart Compose introduced by Gmail also rely on machine learning and are great tools to save time while drafting e-mails [23]. They suggest the appropriate sentences while composing a new e-mail or replying to a received e-mail, with the support of a large, predefined training set.

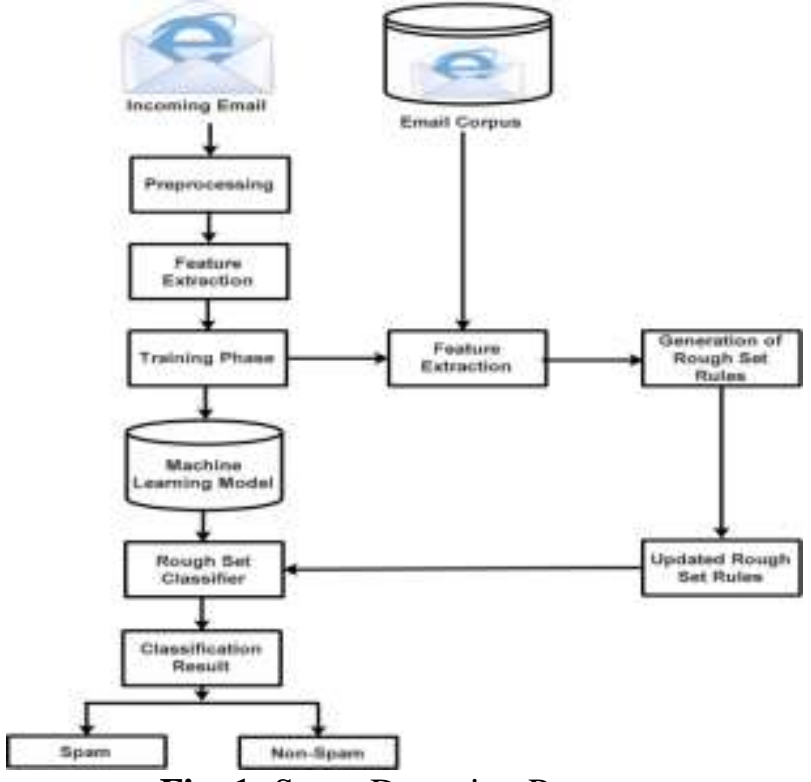

Fig. 1: Spam Detection Process

E-mail filtering is another area where machine learning finds applications. Statistical techniques such as a Naïve Bayes classifier could be implemented to filter spam messages. Other algorithms like logistic regression and neural networks could also be used for the same [24]. The widely applied spam filtering techniques, as described in [24], are listed below.

i. $\quad$ Content based filtering technique

ii. Case based spam filtering method

iii. Heuristic or rule based spam filtering technique

iv. Previous likeness based spam filtering technique

v. Adaptive spam filtering technique

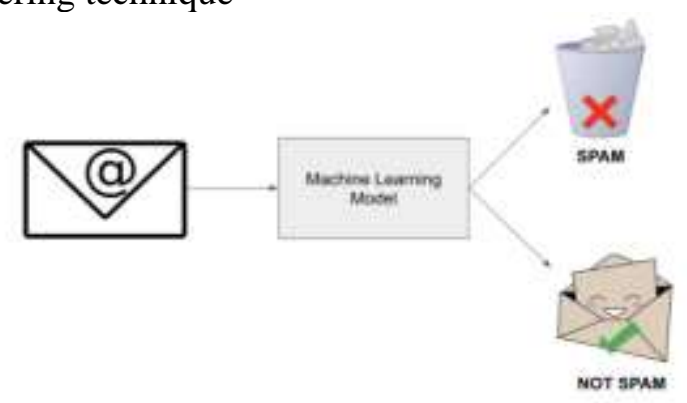

Fig. 2: Spam Filtering Model

\subsection{Google Maps:}

Google Maps is another popular service from the house of Google. It helps commuters and tourists by predicting traffic and suggesting an appropriate route for them to reach their destinations. It acts as a platform that provides business listings, driving directions, public transport details as well as real-time traffic information. Google Maps is available in 220 countries and every day, more than 1 billion kilometres are navigated with its assistance [25].

Satellite imagery has a prominent role in identifying places in the world. It shows where streets, open fields, structures, and businesses are situated in a region. Google collects billions of pictures from different countries across the world and these pictures along with user-contributed data help in identifying landmarks. In a recent blog post by Johann Lau, Product Manager at Google Maps, it has been revealed that data from different sources, including local government data, aggregate location data, historical traffic patterns, real-time feedback from users, and incident reports, is being collected to predict traffic [25]. 


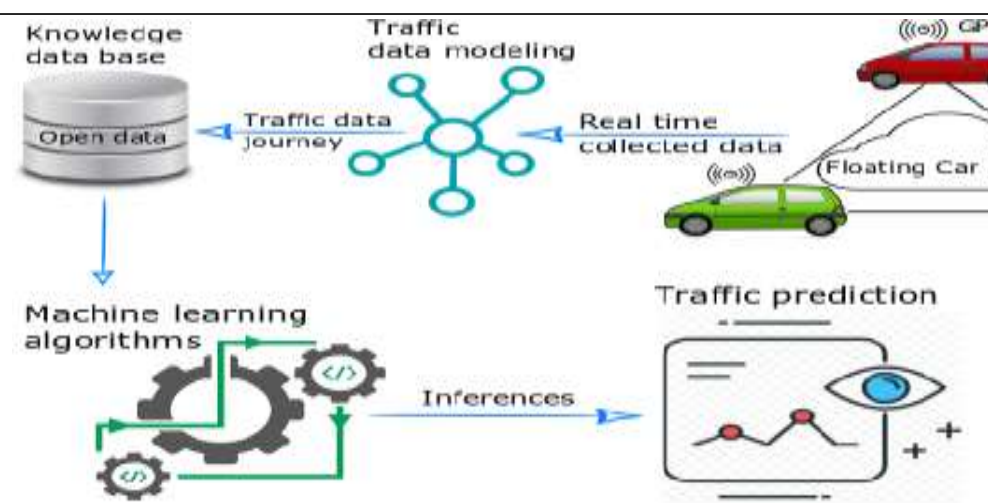

Fig. 3: Traffic Prediction Model in Google Maps

Google, in association with DeepMind, the artificial intelligence subsidiary of Alphabet Inc., has developed techniques to improve traffic prediction capabilities. It applies the concept of Graph Neural Networks (GNN) to lower the cases of inaccurate expected time of arrivals (ETAs) reported. The prediction system is a combination of a GNN model and a route analyser. The route analyser models 'super segments' from the traffic information and geographical data available. The GNN model then predicts the time to travel for each super segment [26]. The predictive traffic model can identify the routes which are highly likely to experience congestion or heavy traffic and suggests alternative routes accordingly. Other factors such as the quality and condition of roadways, size of the road, direction of travel and the type of vehicle used are also considered while choosing the ideal route. Traffic patterns as recent as the past two to four weeks are also factored in. The real-time data collected from drivers on the road is utilized to make the traffic prediction more accurate.

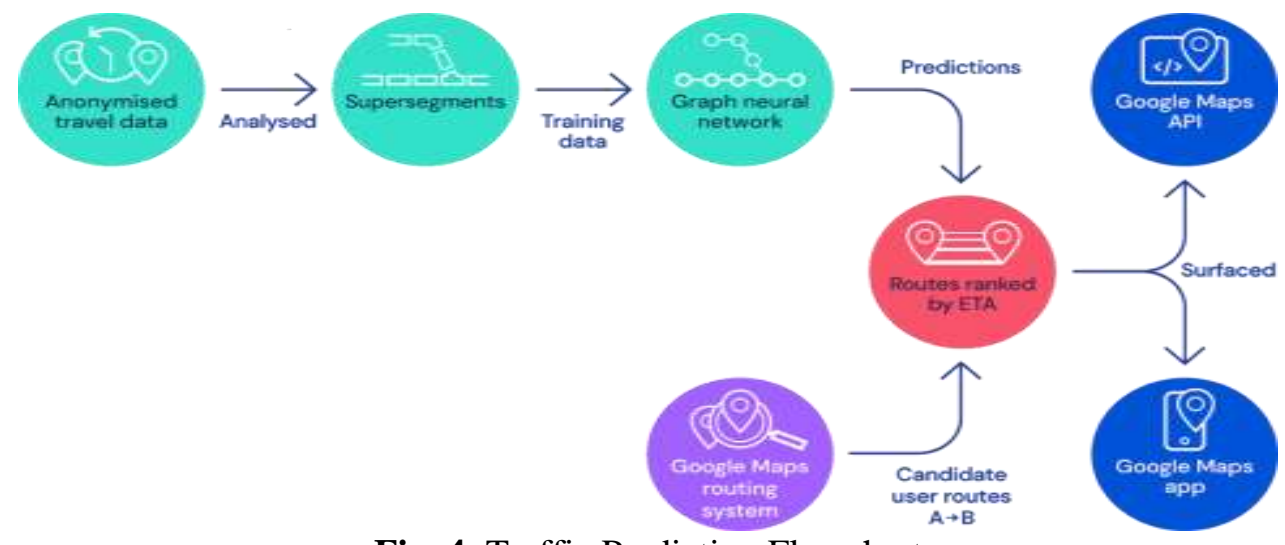

Fig. 4: Traffic Prediction Flowchart

\subsection{Google Photos:}

Computers do not visualize photographs and videos as humans do. For a computer, a picture is pixel and colour information that may be interpreted as shapes. Even though the computer's perception of a photo is not similar to that of human beings, it can be trained to identify certain patterns, objects, colours, or shapes from images. A computer can be trained to identify patterns or the prominent colours in an image that makes up the picture of structures such as a highway or an object such as a traffic sign. This is the same technology that permits users to organize images in Google Photos based on similarity and retrieve them later with a simple keyword search [27].

Just like shapes and patterns, a computer can be trained to identify the presence of a human face in an image. As mentioned in Google's privacy policy [27], this process is called face detection and is used to protect the privacy of individuals whose photos might have been captured by services like Street View. The faces detected in Street View images are blurred to mask the identity of the individuals. Another application of face detection comes in the form of the face grouping feature, where similar faces are grouped together. A tag or description can be assigned to the group as a whole and users can search and manage their photos easily. 


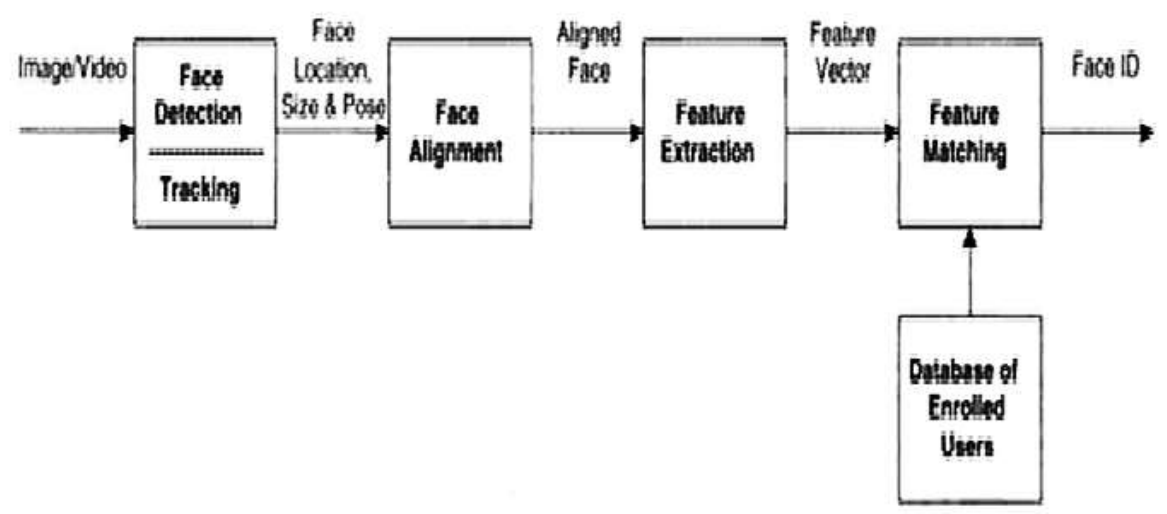

\subsection{Google Assistant:}

Fig. 5: Image Identification Process

A trailblazer among virtual assistant applications, Google Assistant is a voice assistant service provided by Google and can accept commands from users to search on the web or control other devices. It was introduced as the successor to Google Now. Google Assistant allows users to control connected devices and smart homes. Users can open other apps and perform tasks through voice commands. Google Assistant can act as your personal assistant, carrying out many tasks on behalf of the user -add events to Calendar, retrieve information from the web, make restaurant bookings, read out news and weather updates, set reminders, draft e-mails, play music and so much more [28]. Google Assistant is available for most of the Android devices, TVs, smart speakers, wearables, cars, etc. [29]. It can communicate with third-party electronic appliances as well. Several products are supported, including popular brand names like Nest, LG ThinQ, Bajaj Smart, Philips Hue, and Kohler.

AI plays a pivotal role in the working of Google Assistant. Natural language processing (NLP), another application of machine learning, enables it to understand what the user is speaking [30]. Natural Language Processing is that branch of AI which deals with developing systems and machines to understand human language and also translate from one language to another (such as Google Translate). Google Assistant is the confluence of multiple domains, namely linguistics, computational linguistics, and machine learning. Google Assistant analyses and processes the words spoken to it and understands the meaning and context. Based on this understanding, appropriate action is executed or responses are framed.

\section{FINANCIAL STATEMENTS (2015-2020) :}

Google has grown to be one of the largest companies in the world in terms of revenue and market capitalization. Much of Google's revenue comes from its proprietary advertising service, Google Ads. Google also brings in income from partner websites through AdSense. Other sources of revenue are the web, media and cloud computing business verticals of Google. Services like Play Store, Google Apps, Google TV, Android, and physical products such as Chromecast and Chromebooks comes under this category [31]. As Google has been reorganized as a subsidiary under Alphabet Inc., the consolidated financial results of the parent company are published every quarter, along with the Google segment's revenue and profits.

In the financial results, Google only discloses six important figures -ad revenue from Google Search and other Google services, ad revenue from AdSense network websites, other revenue, revenue from US territory, revenue from the UK, and revenue from regions other than US and UK [32]. It's difficult to know the contribution of individual products/services to the total revenue. The profit generated by services like YouTube and Google Drive is subject to speculation and the best information in this regard are estimates from brokers and analysts. Based on the figures reported in [33] and [34], the following chart shows the growth in revenue and net income of Google during the period 2015-2020. 


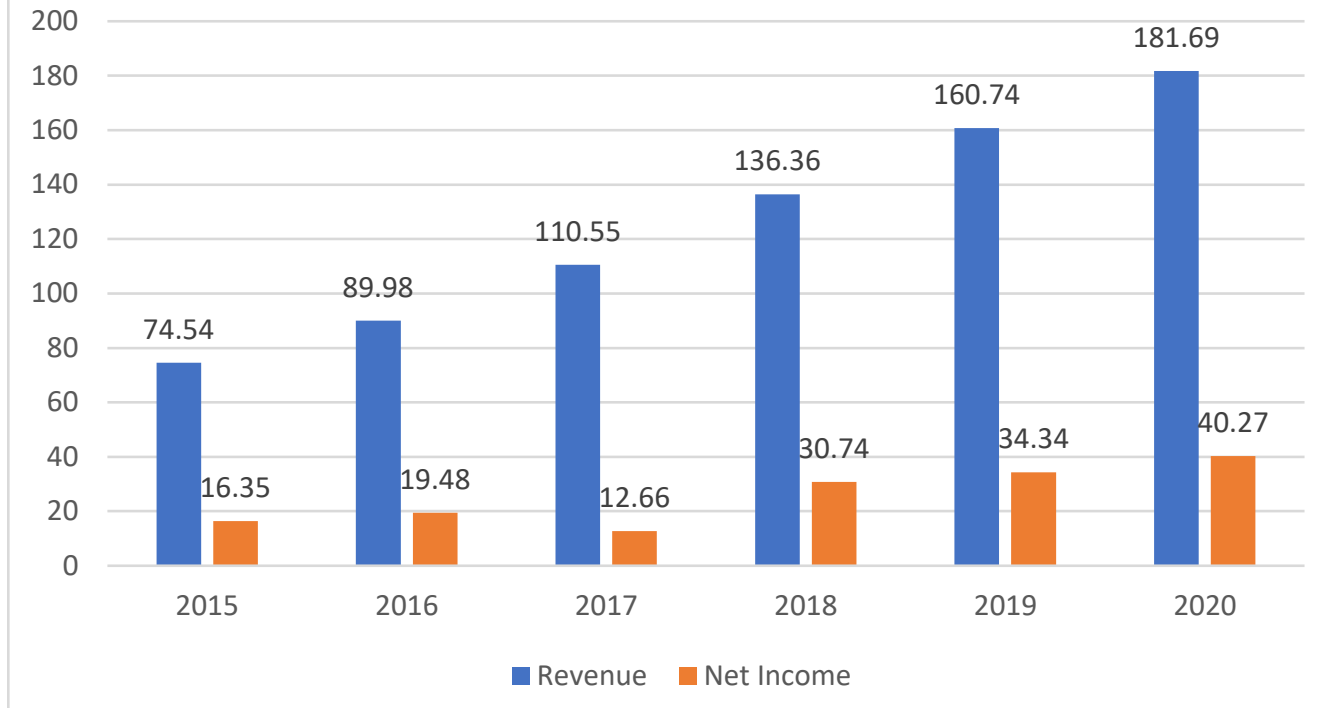

Fig. 6: Revenue and Net Income for Google (2015-2020)

Revenue and net income generated by Google show a steady upward trend from 2015 to 2020 . The greater penetration of the internet among the masses and the corporate restructuring can be cited as reasons for Google's profitability. It must also be noted that ever since Google revamped its services to incorporate ML into them, the revenue has been increasing. Even when the global economy decelerated during the COVID-19 pandemic, Google was able to sail through the troubled market, capitalizing on its machine learning and product engineering expertise, delivering a whole array of services helping the frontline workers as well as citizens and businesses in manoeuvring these difficult times.

\section{STRATEGIC PILLARS OF GOOGLE :}

In the eyes of the world, Google appears to be a technology-driven, geeky, cutting-edge enterprise that acts as our digital guide across various devices and platforms. In reality, Google is just a large advertising organization. The bulk of its revenue comes from Google Ads and Google AdSense. According to business analyst Stijn Schuermans, Google's strategy of connecting ads to eyeballs is based on three pillars - flatten, expand, and mine [35].

\subsection{Flatten:}

The foundation of Google's strategy is to bring down any obstacles that lie between consumer eyeballs and ads. It flattens or clears the path between the customer and ads. Google provides several services for free, thereby increasing the avenues where advertisements can be placed. Google offers operating systems like Android and Chrome OS, thus commoditizing every device it's run on. Google partners with OEM companies to ship their operating system and software products pre-installed on devices, contributing to Google's market share and global presence.

\subsection{Expand:}

After establishing its foothold on the web, Google's subsequent objective is to grow its engagement with users. Consider the example of Google Workspace. Google takes care of all your professional and personal digital needs through a large portfolio of services - Gmail, Calendar, Meet, Hangouts, Android, Blogger, Chrome, Drive, Google Maps, YouTube, Forms, Google Translate and so many more. This way, Google is positioning itself as an essential element in peoples' lives. All of these services offered by Google provide more ad real-estate, i.e., more space to display ads.

\subsection{Mine:}

Schuermans writes that after flattening and expanding, Google makes use of data-mining to learn about the users' behaviour. This makes the advertisements more personalized to the user's interests, which 
increases the click-through rate (CTR) and there is a greater chance of the ad converting to a sale. Google places advertisements on top of search results, showcasing products related to what the user searched. The search history is also used to display ads, within Google products as well as in partner websites. Google could collect more data about the user by scanning the content of e-mails, social interactions, YouTube watch history, GPS location, and check-ins.

\section{GOOGLE'S STAKEHOLDERS :}

Google has several classes of stakeholders owing to the dominant position it has in the World Wide Web. With every addition to Google's bouquet of products and services, there is a subsequent addition in the stakeholder community. To maintain profitability while acting in the best interests of the stakeholders, Google has to adopt appropriate corporate social responsibility (CSR) strategies. Google's present CSR policy is extensive and at par with global standards and public expectations.

The stakeholders of Google can be classified into six groups based on shared interests [36]. The current CSR policy is directed towards delivering value to these stakeholders. The list of stakeholder groups is produced below -

1. Users

2. Employees

3. Advertisers and other customers

4. Investors

5. Governments

6. Communities

Users simply mean people who use Google's products. Businesses that use Google's products are also considered users. They could be paying as well as non-paying users. Consider the example of Google Chrome. It is released free of cost to all types of users. As in the case of Gmail, there is a paid scheme, where the user gets additional storage and add-on services. Users only have an interest in the utility of the products offered to them. The positive opinion from users translates to the popularity of Google which in turn becomes the firm's business value. Google's CSR policy follows a user's first approach. Google's user-centric approach can be understood from the philosophy that "Focus on the user and all else will follow" [37]. Users constitute the most important stakeholder group of Google and while designing products and services, users' needs are given the highest priority.

Google's commitment and responsibility towards its employees are accomplished through a competitive compensation package and a fun workplace design. Google provides a dynamic environment to work, with flexible hours, health benefits, and free meals. Employees have access to recreation spaces where they can discuss ideas with colleagues, play games, do exercise or take short naps. Google came at position 6 in Glassdoor's "Best Places to Work in 2021" list for the US [38]. In the list for Canada, Google was placed in the first position.

\section{GOOGLE'S CORPORATE SOCIAL RESPONSIBILITY :}

Corporate social responsibility (CSR) is the concept which proposes that a business has certain responsibilities towards the public and society. Corporates that have a well-defined CSR plan usually operate in a socially responsible manner. Assigning funds for CSR activities and making impactful interventions in society adds to the overall goodwill enjoyed by the company.

Traditionally, corporate social responsibility can be divided into four categories- environmental responsibility, philanthropic responsibility, ethical responsibility, and economic responsibility [39]. Environmental responsibility has the objective to reduce the impact on the environment and transform processes to be more sustainable. Every year, Google publishes an environmental report which is a summary of Google's CSR efforts focused on environment-friendly operations and sustainability. In the 2020 environment report, neutralization of legacy carbon footprint was cited as an achievement [40]. By 2030, Google aims to switch to completely carbon-free energy sources and increase the capacity by $5 \mathrm{GW}$ by investing in sustainable energy infrastructure.

Ethical responsibility points to the concept that an organization has to uphold fairness and ethics in their business. It is important to ensure that all the important stakeholders of the business including investors, directors, executives, suppliers, customers and employees are treated fairly. It is worthy to note that Google has released a public document called the 'Google Code of Conduct' which are a set of 
guidelines to employees and other stakeholders on the expected behaviour from them. 'Google Code of Conduct' concludes with the phrase "Don't be evil" and that essentially captures the moral and ethical standing of Google as an organization [41].

Philanthropic responsibility refers to the donations and contributions made by businesses to charitable causes, which may or may not be directly related to their line of business. A recent example of Google's philanthropic efforts would be the ₹135 crore grant given to India in April 2021 to tackle the COVID crisis [42].

Economic responsibility affirms that business must not just be profit-driven, but it must have the goal of positively impacting the environment, people, and society. One instance of Google's economic responsibility would be offering educational resources and products free of cost to students and educators. Google also provides Ad grants, which allows governmental organizations and NGOs to propagate their message to a larger audience through Google Ads free of cost.

\section{SWOT ANALYSIS :}

SWOT analysis is a very common management tool used by companies in assessing different factors involved before making a strategic business decision while focusing on long-term stability and sustainability [2]. The acronym SWOT is made from the first letters of the four factors analysed, namely strengths, weaknesses, opportunities, and threats. The strength and weaknesses can be considered as internal factors, while the opportunities and threats exist in the wider external environment. Google is the leader in search and enjoys the privilege of being a valued brand globally. While Google has established its stronghold in some domains, it suffers from several weaknesses in some other domains. As far as Google is concerned, the steadily increasing internet penetration rate opens doors to new opportunities and at the same time brings in threats to the business. The SWOT factors are subject to personal interpretations because what one individual perceives as an opportunity might be identified as a threat by another. Brianna Parker of bstrategyhub.com makes a comprehensive evaluation of Google's strengths, weaknesses, opportunities, and threats [43], as summarized in the following subsections.

\subsection{Strengths:}

1. Dominant player in online search

2. Second most valuable brand globally

3. Infrastructure - Google has the technological know-how and computational resources to provide a 24/7 uptime for Google search and allied services.

4. High revenue

5. Adaptability

6. Rapid growth

7. Strong R\&D division

\subsection{Weaknesses:}

1. Secrecy about search algorithms

2. Overdependence on advertisement

3. Large organizations like Johnson \& Johnson, AT\&T, Verizon, and even the British government have boycotted the advertising services of Google citing the reason that their ads were placed along with extremist content and videos.

4. Violation of the European Union's online privacy rules

5. Failure to be part of the social media revolution

6. Poor pricing strategy of YouTube TV

7. Employees protest as part of the 'Black Lives Matter' movement, pressuring Google to stop providing G-suite services to police departments.

\subsection{Opportunities:}

1. Acquisition of Fitbit and entry into the wearables market

2. Android OS

3. Increasing revenue share of the cloud services segment

4. Remote work and collaboration tools

5. Expanding services to emerging markets

6. Strategic diversification to improve non-advertising revenue

\subsection{Threats:}


1. A decline in advertising market share

2. Allegations of gender bias in Google

3. Antitrust controversies

4. Strong competition from Facebook and Amazon

5. Economic uncertainty due to pandemic

6. Anti-encryption drive against Google and other tech giants

7. Tension with China

It can be understood that the pandemic and global switch to remote work has contributed to the greater popularity of collaboration and communication tools of Google like Gmail, Google Meet, Google Classroom, and Google Drive. Google is in a cycle of constant innovation, delivering new products and services that align with the users' requirements and go on to set the standards in the industry.

\section{CONCLUSION :}

Google can be called the foster child of the World Wide Web. The journey of Google from very humble beginnings as a page ranking algorithm to being an indispensable element of today's world and constantly on the lookout for the "Next Big Thing" captures the growth and reach of the web as well. When the dot com bubble burst and several companies languished, Google was able to push through the rubble, solidifying its position as a tech leader. The last decade witnessed an overhaul of Google, both in terms of corporate structure and the services offered. Embracing machine learning has improved user engagement across all platforms and makes Google services highly personalized and relevant. Google Assistant has become a stellar example of narrow AI and is miles ahead of its competitors. In a way, the world sees Google as the custodian of information, a seer, an oracle. We look up to it to bring about the next technological revolution and lead humanity ahead. With the company actively exploring revenue streams other than advertisements, expectations are mounting about the gizmos and surprises being crafted in Google's "garage"! In Google we trust!

\section{REFERENCES :}

[1]. Gaubys, J. (n.d.). Search Engine Market Share in 2021 [Jul '21 Update]. Oberlo. https://www.oberlo.in/statistics/search-engine-market-share. [Accessed: 18-Jul-2021].

[2]. Darkwah, K. (n.d.). Google's Business Strategy: An Empirical Analysis of the Strengths, Weakness, Opportunities, and Threats (SWOT) of Googles Business Strategy. Academia.edu. https://www.academia.edu/24732011. [Accessed: 18-Jul-2021].

[3]. Mohsin, M. (2021, June 30). 10 Google Search Statistics You Need to Know in 2021. Oberlo. https://www.oberlo.in/blog/google-search-statistics. [Accessed: 18-Jul-2021].

[4]. Cioffi, R., Travaglioni, M., Piscitelli, G., Petrillo, A., \& De Felice, F. (2020). Artificial Intelligence and Machine Learning Applications in Smart Production: Progress, Trends, and Directions. Sustainability, 12(2), 492.

[5]. About Google, Our Culture \& Company News. Google. (n.d.). https://about.google/. [Accessed: 18Jul-2021].

[6]. Gennaro Cuofano, P., (2020, March 17). Google Mission Statement and Vision Statement In A Nutshell. Four Week MBA. https://fourweekmba.com/google-vision-statement-missionstatement/. [Accessed: 18-Jul-2021].

[7]. 2004 Founders' IPO Letter. Alphabet Investor Relations. (n.d.). https://abc.xyz/investor/foundersletters/2004-ipo-letter/. [Accessed: 18-Jul-2021]. Kashyap, G. k. (2019, November 24).

[8]. What is Google and How it came into existence. Times Nows Zone. https://www.timesnows.com/what-is-google-and-how-it-came-into-existence/. [Accessed: 18-Jul2021].

[9]. Page, L., Brin, S., Motwani, R., \& Winograd, T. (1999). The PageRank Citation Ranking : Bringing Order to the Web. WWW 1999. 
[10]. Aithal, P. S. (2017). Industry Analysis-The First Step in Business Management Scholarly Research. International Journal of Case Studies in Business, IT and Education (IJCSBE), 1(1), 113.

[11]. History of Google - From 1996 to 2020. Mirror Review. (2020, December 30). https://www.mirrorreview.com/history-of-google-from-1996-to-2019/. [Accessed: 18-Jul-2021].

[12]. Rosenberg, S. (2013, July 3). Let's Get This Straight: Yes, there is a better search engine. Salon. https://www.salon.com/1998/12/21/straight_44/. [Accessed: 18-Jul-2021].

[13]. Siegler, M. G. (2010, September 29). When Google Wanted to Sell to Excite for Under \$1 Million - And They Passed. TechCrunch. https://techcrunch.com/2010/09/29/google-excite/. [Accessed: 18-Jul-2021].

[14]. Hu, J. (2004, February 18). Yahoo dumps Google search technology. CNET. https://www.cnet.com/news/yahoo-dumps-google-search-technology/. [Accessed: 18-Jul-2021].

[15]. Gwern. (2009, January 21). Wikipedia \& Knol: Why Knol Already Failed. · Gwern.net. https://www.gwern.net/Wikipedia-and-Knol. [Accessed: 18-Jul-2021].

[16]. Tran, S. K. (2017). GOOGLE: a reflection of culture, leader, and management. International Journal of Corporate Social Responsibility, 2(10), 1-14.

[17]. Aithal, P. S. (2017). Company Analysis-The Beginning Step for Scholarly Research. International Journal of Case Studies in Business, IT and Education (IJCSBE), 1(1), 1-18.

[18]. Patterson, S. M. (2015, August 13). Understanding Google's Alphabet structure (think, alpha bet). CIO. https://www.cio.com/article/2970543/understanding-google-s-alphabet-structure-thinkalpha-bet.html. [Accessed: 15-Jul-2021].

[19]. Hartmans, A., \& Sandoval, G. (2018, July 12). The company formerly known as Google is far bigger than most people realise. Business Insider Australia. https://www.businessinsider.com.au/alphabet-google-company-list-2017-4. [Accessed: 15-Jul2021].

[20]. Google. (n.d.). Announcing Google Workspace, everything you need to get it done, in one location | Google Cloud Blog. Google. https://cloud.google.com/blog/products/workspace/introducinggoogle-workspace. [Accessed: 15-Jul-2021].

[21]. Waypoint - The official Waymo blog: Waymo's early rider program, one year in. Waymo Blog. (2018, June 13). https://blog.waymo.com/2019/08/waymos-early-rider-program-one-year-in.html. [Accessed: 15-Jul-2021].

[22]. Aithal, P. S. (2017). ABCD Analysis as Research Methodology in Company Case Studies. International Journal of Management, Technology, and Social Sciences (IJMTS), 2(2), 40-54.

[23]. Waypoint - The official Waymo blog: In the cab with the Waymo Driver: How trucks help advance our self-driving technology. Waymo Blog. (2020, October 13). https://blog.waymo.com/2020/10/How\%20trucks\%20help\%20advance\%20our\%20selfdriving\%20technology.html. [Accessed: 15-Jul-2021].

[24]. D'onfro, J. (2015, October 23). Google is 're-thinking' all of its products to include machine learning. Business Insider. https://www.businessinsider.in/tech/google-is-re-thinking-all-of-itsproducts-to-include-machine-learning/articleshow/49499694.cms. [Accessed: 13-Jul-2021].

[25]. Improving Malicious Document Detection in Gmail with Deep Learning. Google Online Security Blog. (2020, February 25). https://security.googleblog.com/2020/02/improving-maliciousdocument-detection.html. [Accessed: 13-Jul-2021].

[26]. Garun, N. (2020, July 6). How to enable and use Gmail's AI-powered Smart Reply and Smart Compose tools. The Verge. https://www.theverge.com/21315189/gmail-ai-smart-reply-composetools-enable-turn-on-how-to. [Accessed: 13-Jul-2021]. 
[27]. Dada, E. G., Bassi, J. S., Chiroma, H., Abdulhamid, S. M., Adetunmbi, A. O., \& Ajibuwa, O. E. (2019). Machine learning for email spam filtering: review, approaches and open research problems. Heliyon, 5(6), e01802.

[28]. Lau, J. (2020, September 3). Google Maps 101: How AI helps predict traffic and determine routes. Google. https://blog.google/products/maps/google-maps-101-how-ai-helps-predict-traffic-anddetermine-routes/. [Accessed: 13-Jul-2021].

[29]. Patra, I. (2020, September 11). Google explains how it predicts traffic, plans routes on Maps. The Hindu. https://www.thehindu.com/sci-tech/technology/google-explains-how-it-predicts-trafficplans-routes-on-maps/article32582439.ece [Accessed: 13-Jul-2021].

[30]. Google. (n.d.). How Google uses pattern recognition - Privacy \& Terms. Google. https://policies.google.com/technologies/pattern-recognition?hl=en-US. [Accessed: 12-Jul-2021].

[31]. Pocket-lint. (2021, March 25). What is Google Assistant and what can it do? Pocket. https://www.pocket-lint.com/apps/news/google/137722-what-is-google-assistant-how-does-itwork-and-which-devices-offer-it. [Accessed: 12-Jul-2021].

[32]. Google. (n.d.). Google Assistant, your own personal Google. https://assistant.google.com/intl/en_in/. [Accessed: 10-Jul-2021].

[33]. The Technologies behind Google Assistant. SCI planet. (n.d.). https://www.bibalex.org/SCIplanet/en/Article/Details.aspx?id=13640\#: :text=AI\%20is\%20at\%2 0the\%20core, language\%20processing\%20and\%20machine\%20learning.\&text=Google\%20Assist ant\%20processes\%20inputs\%20and,how\%20a\%20human\%20being\%20would. [Accessed: 10Jul-2021].

[34]. Rosenberg, E. (2021, June 9). How Google Makes Money (GOOG). Investopedia. https://www.investopedia.com/articles/investing/020515/business-google.asp [Accessed: 10-Jul2021].

[35]. Edwards, J. (2015, July 10). We finally got some really good data on just how much money Google makes from YouTube and Google Play. Business Insider. https://www.businessinsider.in/tech/wefinally-got-some-really-good-data-on-just-how-much-money-google-makes-from-youtube-andgoogle-play/articleshow/48023654.cms. [Accessed: 8-Jul-2021].

[36]. Johnson, J. (2021, February 8). Google: annual revenue. Statista. https://www.statista.com/statistics/266206/googles-annual-global-revenue/. [Accessed: 8-Jul2021].

[37]. Alphabet Net Income (Annual): YCharts. (n.d.). https://ycharts.com/companies/GOOG/net_income_annual. [Accessed: 8-Jul-2021].

[38]. Flatten, Expand, Mine: The three pillars of Google's strategy. SlashData. (n.d.). https://www.slashdata.co/blog/flatten-expand-mine-the-three-pillars-of-googles-strategy. [Accessed: 8-Jul-2021].

[39]. Meyer, P. (2017, January 28). Google Stakeholders \& Corporate Social Responsibility (CSR). Panmore Institute. http://panmore.com/google-stakeholders-corporate-social-responsibility-csranalysis. [Accessed: 8-Jul-2021].

[40]. Ten things we know to be true. Google. (n.d.). https://about.google/philosophy/. [Accessed: 8-Jul2021].

[41]. Paulise, L. (2021, January 15). Here Are Glassdoor's Best Places To Work In 2021. Forbes. https://www.forbes.com/sites/lucianapaulise/2021/01/15/here-are-glassdoors-best-places-to-workin-2021. [Accessed: 8-Jul-2021].

[42]. Types of Corporate Social Responsibility to Be Aware Of. Business Insights - Blog. (2021, April 8). https://online.hbs.edu/blog/post/types-of-corporate-social-responsibility. [Accessed: 6-Jul2021]. 
[43]. Porat, R. (2021, March 2). Our 2020 environmental report. Google. https://blog.google/outreachinitiatives/sustainability/2020-environmental-report. [Accessed: 6-Jul-2021].

[44]. Google Code of Conduct. Alphabet Investor Relations. (n.d.). https://abc.xyz/investor/other/google-code-of-conduct. [Accessed: 6-Jul-2021].

[45]. Bureau, O. (2021, April 26). Google announces ₹135 crore aid to India to fight Covid-19. The Hindu Business Line. https://www.thehindubusinessline.com/news/google-announces-135-croreaid-to-india-to-fight-covid-19/article34412093.ece. [Accessed: 6-Jul-2021].

[46]. Mistry, R. (2020, September 13). Google SWOT Analysis 2020: SWOT analysis of Google. Business Strategy Hub. https://bstrategyhub.com/swot-analysis-of-google-2019-google-swotanalysis. [Accessed: 6-Jul-2021]. 